\title{
Childhood Diarrhea in Central Ethiopia: Determining Factors for Mothers in Seeking Modern Health Treatments
}

\author{
Ephrem Mamo Gebrehiwot ${ }^{1}$, Tezera Moshago Berheto ${ }^{2,}$, Alemayehu Worku $^{3}$, \\ Tadele Dana Darebo ${ }^{4}$, Ephrem Lejore Sibamo ${ }^{5}$ \\ ${ }^{1}$ Department of Public Health, Faculty of Health Sciences, Assosa University, Assosa, Ethiopia \\ ${ }^{2}$ School of Public Health, College of Health Sciences, Wolaita Soddo University, Soddo, Ethiopia \\ ${ }^{3}$ School of Public Health, College of Health Sciences, Addis Ababa University, Addis Ababa, Ethiopia \\ ${ }^{4}$ School of Public Health, College of Health Sciences, Wolaita Soddo University, Soddo, Ethiopia \\ ${ }^{5}$ Hadiya Zonal Health Department, Hossana, Ethiopia
}

\section{Email address:}

ephremmamo@yahoo.com (E. M. Gebrehiwot),moshagot1@gmail.com (T. M. Berheto), alemayehuwy@gmail.com (A. Worku), tadeledana@gmail.com (T. D. Darebo),ephrlej@gmail.com (E. L. Sibamo)

\section{To cite this article:}

Ephrem Mamo Gebrehiwot, Tezera Moshago Berheto, Alemayehu Worku, Tadele Dana Darebo, Ephrem Lejore Sibamo. Childhood Diarrhea in Central Ethiopia: Determining Factors for Mothers in Seeking Modern Health Treatments. Science Journal of Clinical Medicine. Vol. 4, No. 1, 2015, pp. 4-9. doi: 10.11648/j.sjcm.20150401.12

\begin{abstract}
Background: Diarrhea remains one of the principal causes of morbidity and mortality in children in developing countries. A major contributing factor is the treatment provided by the mother. The current study was carried out to assess the behavior of mothers in seeking modern health care and its impact on childhood diarrhea in the Central Ethiopia. Methods: A comparative cross-sectional study was conducted in randomly selected mothers or care providers who had at least one child under five years who had experienced diarrhea within the previous two weeks. Descriptive statistics, bivariate, and multiple regression analyses were performed. $P$-values less than 0.05 and $95 \%$ confidence intervals were used to determine an association between independent and dependent variables. Results: Ninety-five percent (413/434) mothers or care-providers completed the survey. Seventy-seven percent of urban and $54.4 \%$ of rural women sought care at a health institution. Mothers who lived in urban areas were four and half times more likely to seek modern treatment than rural dwellers [OR $(95 \% \mathrm{CIs})=4.49(2.07,9.7)]$, while mothers with grade $9-12$ levels of literacy were nine times more likely to seek modern treatment than illiterate mothers $[8.88(1.15,68.6)]$. Households using latrines and with income greater than 30USD per month were 4.6 and 3.3 times more likely to seek modern treatment than who used open fields and who earned less than 30 USD per month, respectively $[4.62(1.84,11.60)$ and $3.31(1.45,7.54)]$. Increased fluids were given to only $50.8 \%$ urban and $26 \%$ rural children with diarrhea. Notably, fluids were stopped in $3.8 \%$ and $11.4 \%$ of urban and rural children, respectively, while fluid intake was reduced in $6.8 \%$ urban and $19.2 \%$ rural children. Conclusion: Socioeconomic factors such as the educational status of the women, the distance of health care facilities, and the method of disposing of excreta were significantly associated with the behavior of the mother in seeking modern treatment. An urgent requirement for improved health education and infrastructure for women is needed.
\end{abstract}

Keywords: Health Care Seeking Behavior, Diarrhea, Childhood, Central Ethiopia

\section{Introduction}

Diarrheal disease remains one of the principal causes of morbidity and mortality in children[1] with nearly one in five child deaths, approximately 1.5 million each year, being due to diarrhea [2].Furthermore, diarrhea also account for one in nine child deaths worldwide, making diarrhea the second leading cause of death among children under the age of five
$[1,2]$. Diarrhea is particularly problematical in the developing countries of Asia, Africa, and Latin America, resulting in the deaths of millions of children under five [2]. In Ethiopia, the child mortality rate in 2007 was 199 per 1,000 births with approximately one in every five deaths being due to diarrheal disease [3,4]. In 2005, an Ethiopian 
demographic health survey reported an $18 \%$ prevalence of two weeks of diarrhea among the under-fives [5], thus highlighting diarrheal disease as one of the major health problem in Ethiopia[5, 6]

Most cases of diarrhea are caused by some type of infection [1]. For example, surveillance studies in rural Bangladesh cited infection as the cause of $86 \%$ of the diarrheal cases; a situation reflected in much of the developing world [2, 3]. Intestinal infections can result in relatively large intestinal losses of fluid and electrolytes that may progress rapidly to cause dehydration [2, 7]. Another associated important issue is the problem of nutritional deficiencies $[1,7]$. Both of these outcomes can lead to death in children $[7,8]$.

The rapid and appropriate management of acute diarrhea is critical in preventing dehydration and childhood deaths [9]. The use of oral rehydration therapy (ORT), ongoing fluid replacement, and age-appropriate nutritional support represents the foundation for the management of acute diarrheal illnesses among children [4, 8, 10]. Mothers are encouraged to continue feeding children with diarrhea normally but to increase the amount of fluids $[1,7]$. These practices help to reduce dehydration and minimize the adverse consequences of diarrhea on the nutritional status of the child [1].

Despite the potential of such treatment to substantially reduce child mortality, a large number of children in developing countries die due to a delay in seeking care at, or advice from, a health facility[2]. This is of particular importance in countries like Ethiopia, where access to health services is limited. The effective management of childhood illness involves a partnership between families and health workers. Families need to be able to respond appropriately when their children are sick, seek timely assistance when children need additional care, and administer the recommended treatments [6].

\section{Materials and Methods}

\subsection{Study Design}

A community based comparative cross-sectional study was conducted in the Arsi Zone, one of 12 zones situated in the Central Ethiopia, Oromiya Regional State of Ethiopia, to examine the factors determining the behavior of mothers or care-givers in seeking modern health care. Based on the 2007 national census projected to 2011, Arsi Zone has an estimated total population of $3,135,686$, of which 1,775,076 are women. Approximately $19 \%$ of the total population are urban dwellers and the zone has an estimated population density of 132.17 people per square kilometer[11].

The data was collected during January and February 2011. A two-stage sampling method was used to select the study participants. Eight rural kebeles and one town were selected using a simple random sampling method. The sample size was distributed between town and rural kebeles in a ratio of $1: 2$. The first sample from a site was identified randomly and subsequent households were identified systematically until the total sample needed was achieved. In the absence of children under five with diarrhea or who had experienced diarrhea within the previous two weeks, then the next house was included. If there were more than five children under the age of five in a particular household then only one child was selected using a lottery method.

Data collection was carried out using intervieweradministered, pre-tested, structured, and standardized questionnaires. The questionnaire was prepared in English and translated to Afan Oromo (the local language) and subsequently translated back to English. Health Extension Workers collected the data by house-to-house visiting. Supervisors followed the data collectors and provided any necessary correction on the spot.

Ethical approval of the study was obtained from the Addis Ababa University Ethical review board. The participants were informed about the purpose of the study and oral consent was obtained from each study participant prior to conducting the interview.

\subsection{Sample Size Determination}

A sample size calculation was performed using the STATCALC program of EPI INFO, version 6.2, to estimate the two population proportions of urban and rural women who sought modern treatment of diarrheal disease. The following assumptions were made to obtain the maximum sample size: $\mathrm{P}_{1}=35 \%$ of urban mothers who sought modern treatment; $\mathrm{P}_{2}=22 \%$ of rural mothers who seek modern treatment [5]. The power to detect a significant difference between $\mathrm{P} 1$ and $\mathrm{P} 2$, if it existed, was $(1-\beta)=80 \%, \mathrm{Z}_{\alpha / 2}=$ 1.96 and $Z_{\beta}=0.84$. The urban to rural ratio was $1: 2$, the sample size for urban $=n 1$ and rural $=n 2=2(n 1)$, sample size $=414$, and $5 \%$ non-response rate $=434\left(\mathrm{n}_{1}=144\right.$ and $\mathrm{n}_{2}=290$ )

\subsection{Statistical Analysis}

All returned questionnaires were manually checked for the completeness and consistency of responses. The data was then entered into the EPI INFO version 3.5.1 software and analyzed using SPSS version 17. Both descriptive and analytical statistical test procedures were utilized. Multivariate analysis was used to determine the presence of any statistically significant associations between the dependent and the independent variables. A $P$-value of $<0.05$ was considered statistically significant.

\section{Results}

The socio-economic details of the mothers and careproviders are summarized in Table 1 . Of the 434 participants recruited, $413(95.2 \%)$ provided a complete data return. The ratio of urban to rural subjects was $1: 2$. A total of $64 \%$ of the women were aged between 20-29 years, of whom $80(60.5 \%)$ and $184(65.5 \%)$ were from urban and rural areas, respectively. The assessment of educational status showed that $24.2 \%$ of the urban and $31.7 \%$ of the rural women was 
illiterate. Comparable numbers of the urban (36.4\%) and rural women $(36.3 \%)$ attained primary school education (grades 1-6). The number of women receiving secondary education (grades $7-12$ ) decreased to $31.1 \%$ and $18.8 \%$ of the urban and rural women, respectively. A total of 413 children with diarrhea were studied, of whom $56.9 \%$ were male and $43.1 \%$ were female. The majority of these children $(78.5 \%)$ were aged between 12-59 months; with 38.3\% aged 12-23 months and $40.4 \%$ aged $24-59$ months.

Muslim was the dominant religion in both the urban (61\%) and rural $(66.2 \%)$ areas. Almost all $(99.2 \%)$ of the urban dwellers but only $60.9 \%$ of the rural dwellers lived five or less kilometers from the nearest health center or private drug shop. The majority of both urban and rural women $(97.0 \%$ versus $92.2 \%$ ) used latrines for excreta disposal.

Table 1. Socio-demographic and household characteristics of mothers and care-providers; Arsi Zone, Ethiopia, January 2011 ( $n=413$ ).

\begin{tabular}{|c|c|c|c|}
\hline Variable & Urban, $n=132(32 \%)$ & Rural, $n=282(68 \%)$ & Total, $n=413(100 \%)$ \\
\hline \multicolumn{4}{|c|}{ Mother age (years) } \\
\hline$\leq 19$ & $6(4.5 \%)$ & $6(2.1 \%)$ & $12(2.9 \%)$ \\
\hline $20-29$ & $80(60.6 \%)$ & $184(65.5)$ & $264(63.9 \%)$ \\
\hline $30-39$ & $31(23.5 \%)$ & $75(26.7 \%)$ & $106(25.7 \%)$ \\
\hline $40-49$ & $15(11.3 \%)$ & $16(5.7 \%)$ & $31(7.6 \%)$ \\
\hline \multicolumn{4}{|l|}{ Education status } \\
\hline Illiterate & $32(24.2 \%)$ & $89(31.7 \%)$ & $121(29.3 \%)$ \\
\hline Grade 1-6 & $48(36.4 \%)$ & $102(36.3 \%)$ & $150(36.3 \%)$ \\
\hline Grade 7-8 & $21(15.9 \%)$ & $38(13.5 \%)$ & $59(14.3 \%)$ \\
\hline Grade $9-12$ & $20(15.2 \%)$ & $15(5.3 \%)$ & $35(8.4 \%)$ \\
\hline \multicolumn{4}{|l|}{ Child sex } \\
\hline Male & $75(56.8 \%)$ & $160(56.9 \%)$ & $235(56.9 \%)$ \\
\hline Female & $57(43.2 \%)$ & $121(43.1 \%)$ & $178(43.1 \%)$ \\
\hline \multicolumn{4}{|c|}{ Child age (months) } \\
\hline $12-23$ & $48(36.4 \%)$ & $110(39.1 \%)$ & $158(38.3 \%)$ \\
\hline $24-59$ & $59(44.7 \%)$ & $108(38.4 \%)$ & $167(40.4 \%)$ \\
\hline \multicolumn{4}{|l|}{ Religion } \\
\hline Orthodox & $50(37.9 \%)$ & $85(30.2 \%)$ & $135(32.7)$ \\
\hline Muslim & $81(61 \%)$ & $186(66.2 \%)$ & $267(64.6)$ \\
\hline Protestant & $1(0.8 \%)$ & $10(3.6 \%)$ & $11(2.7)$ \\
\hline \multicolumn{4}{|c|}{ Distance from H.C } \\
\hline$\leq 5 \mathrm{~km}$ & $131(99.2 \%)$ & $171(60.9 \%)$ & $302(73.1 \%)$ \\
\hline$>5 \mathrm{~km}$ & $1(0.8 \%)$ & $110(39.1 \%)$ & $111(26.9 \%)$ \\
\hline \multicolumn{4}{|l|}{ Excreta disposal } \\
\hline Open field & $4(3 \%)$ & $22(7.8 \%)$ & $26(6.3 \%)$ \\
\hline Latrine & $128(97 \%)$ & $259(92.2 \%)$ & $387(93.7 \%)$ \\
\hline
\end{tabular}

\subsection{Home Management of Fluid Intake for Child with Diarrheal Disease}

The comparison of fluid intake is summarized in Figure 1. Increased fluid uptake was reported in $50.8 \%$ of the urban women but only $26.0 \%$ of the rural women. The usual fluid intake for the children was provided by $31.8 \%$ and $24.2 \%$ of the urban and rural women, respectively. Lower numbers of urban women continued with breast milk (19.2\% vs. $6.8 \%)$.
Importantly, $9 \%$ of the women $(3.8 \%$ urban and $11.4 \%$ rural women) stopped fluid intake, while $6.8 \%$ of urban and $19.2 \%$ of rural women reduced fluids to their child. Thirty nine percent of children with diarrhea were treated with some kind of oral dehydration therapy (ORT): $25 \%$ were treated with ORS prepared from an ORS packet and $13.6 \%$ were given RHF.

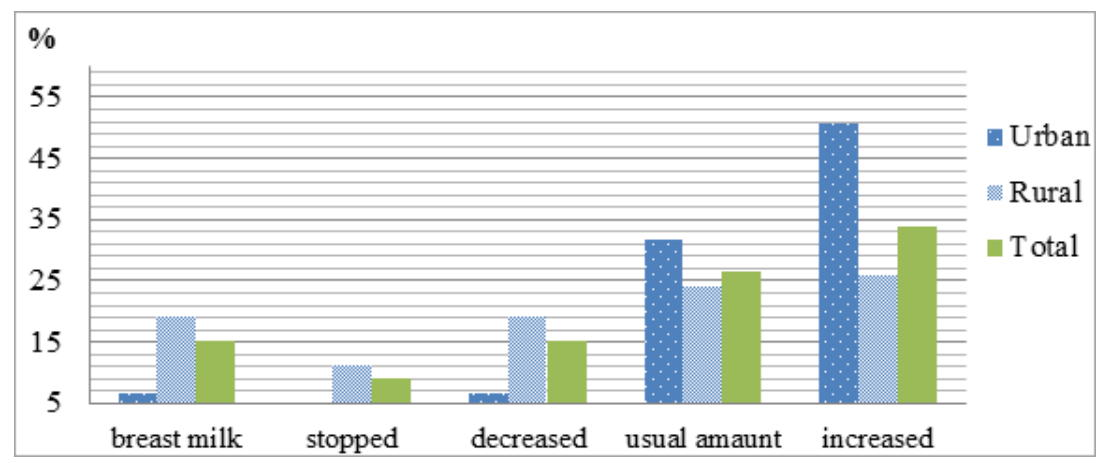

Figure 1. Mothers' home fluid management for child with diarrheal disease. 


\subsection{Behavior of Mother in Seeking Modern Treatment}

The results are summarized in Figure 2. Fifteen percent of the respondent did not seek help for diarrhea. Increased numbers of rural women $(24.1 \%)$ took their children to a traditional treatment place compared to only $7 \%$ of the urban women. In contrast, increased numbers of urban women sought modern assistance from private drug shops (23\% vs. $20 \%)$ and health institutions $(69.9 \%$ vs. $54.4 \%)$ than rural women.

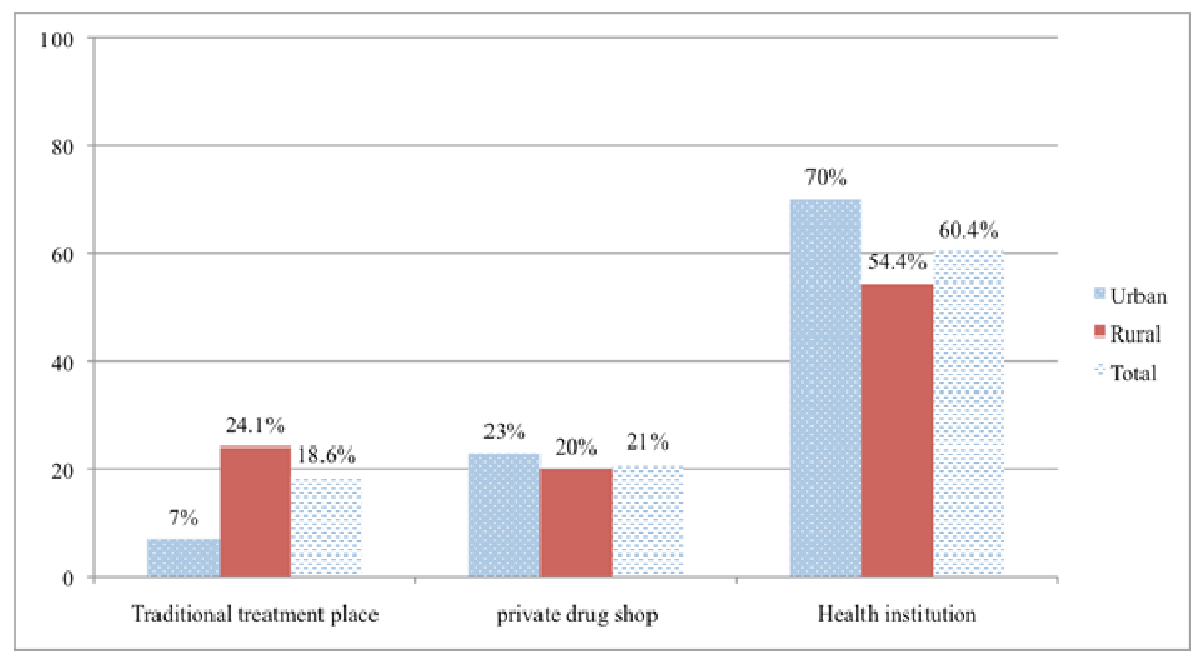

Figure 2. Sources of treatment sought by women with children with diarrhea.

The results of logistic regression analyses performed to identify associations between socio-demographic characteristics and seeking modern treatment by the women are summarized in Table 2. The site of residence, the educational status of the women, income, the distance of health care facilities, and the method of disposing of excreta were all significantly associated with seeking modern treatment by the women. Mothers or care-providers living in urban areas were four and half times more likely to seek modern treatment than rural dwellers [OR $(95 \% \mathrm{CIs})=4.49$ $(2.07,9.7)]$. Women of educational grades $9-12$ were nine times more likely to seek modern treatment than illiterate women [OR $(95 \%$ CIs $)=8.88(1.15,68.6)]$. Households with latrines and incomes exceeding 30USD per month were 4.6 and 3.3 times more likely to seek modern treatment than who used open fields and earning less than 30USD per month, respectively [OR $(95 \%$ CIs $)=4.62(1.84,11.6)]$ and $[\mathrm{OR}$
$(95 \% \mathrm{CIs})=3.31(1.45,7.54)]$. There was also a negative association between health care facilities more than five kilometers distance from home and modern treatmentseeking behavior of mothers compared to health facilities situated less than five kilometers from home [OR $(95 \% \mathrm{CIs})=$ $0.5(0.28,0.88)]$.

Women with children who failed to improve or indeed worsened during the study time were $75 \%$ and $83 \%$ less likely to seek modern treatment than those with children who showed improvement, respectively $[\mathrm{OR} \quad(95 \% \mathrm{CIs})=$ $0.25(0.13,0.49)]$ and $[\mathrm{OR}(95 \% \mathrm{CIs})=0.17(0.05,0.57)]$ (Table; 2).Women who sought professional help sought it quickly with $54.3 \%(67.9 \%$ urban and $45.7 \%$ rural $)$ of the women seeking medical assistance within a two-day period. The remaining $45.7 \%$ mothers went after three or more days of diarrhea.

Table 2. Logistic regression analysis of factors influencing health care seeking behavior for childhood diarrhea to modern treatment; Arsi Zone, January 2011.

\begin{tabular}{lllll}
\hline Variables & \multicolumn{2}{l}{ Soughtmodern treatment } & Crude OR (COR) & Adjusted OR (AOR) \\
\cline { 2 - 3 } & YES (\%) & NO (\%) & 1.00 & 1.00 \\
\hline Residence & & & & $3.41(1.44-8.1)$ \\
Rural & $178(62.9 \%)$ & $61(88.4 \%)$ & & 1.00 \\
Urban & $105(37.1 \%)$ & $8(11.6 \%)$ & 1.00 & $0.56(0.05-5.6)$ \\
Mother age & & $1(1.4 \%)$ & $0.39(0.05-3.17)$ & $0.74(0.06-8.2)$ \\
$\leq 19$ years & $9(3.2 \%)$ & $49(71 \%)$ & $0.62(0.07-5.25)$ & $0.96(0.06-14.4)$ \\
20-29 years & $173(61.1 \%)$ & $14(20.3 \%)$ & $0.5(0.05-5.16)$ & 1.00 \\
$30-39$ years & $78(27.6 \%)$ & $5(7.2 \%)$ & 1.00 & $2.3(0.8-6.58)$ \\
40-49 years & $23(8.2 \%)$ & & $1.74(0.69-4.37)$ & $0.9(0.45-1.83)$ \\
Education status & & $26(37.7 \%)$ & $1.25(0.67-2.3)$ & $1.1(0.42-2.97)$ \\
Illiterate & $79(27.9 \%)$ & $7(10.1 \%)$ & $1.39(0.59-3.25)$ & $4.9(0.59-40.9)$ \\
Read and write & $37(13.2 \%)$ & $26(37.7 \%)$ & $8.88(1.15-68.64)$ & \\
Grade 1-6 & $99(34.9 \%)$ & $9(13 \%)$ & & \\
Grade 7-8 & $38(13.4 \%)$ & $1(1.4 \%)$ & & \\
Grade 9-12 & $30(10.6 \%)$ & & & \\
\hline
\end{tabular}




\begin{tabular}{|c|c|c|c|c|}
\hline \multirow{2}{*}{ Variables } & \multicolumn{2}{|c|}{ Soughtmodern treatment } & \multirow{2}{*}{ Crude OR (COR) } & \multirow{2}{*}{ Adjusted OR (AOR) } \\
\hline & YES (\%) & NO (\%) & & \\
\hline \multicolumn{5}{|l|}{ Child sex } \\
\hline Male & $156(55.1 \%)$ & $45(65.2 \%)$ & 1.00 & 1.00 \\
\hline Female & $127(44.9 \%)$ & $24(34.8 \%)$ & $1.52(0.88-2.64)$ & $1.75(0.95-3.23)$ \\
\hline \multicolumn{5}{|l|}{ Child age } \\
\hline$<6$ month & $19(6.7 \%)$ & $2(2.9 \%)$ & 1.00 & 1.00 \\
\hline 6-11 month & $40(14.1 \%)$ & $14(20.3 \%)$ & $0.3(0.06-1.46)$ & $0.16(0.03-0.9)$ \\
\hline $12-23$ month & $112(39.6 \%)$ & $25(36.2 \%)$ & $0.47(0.1-2.15)$ & $0.37(0.07-1.9)$ \\
\hline $24-59$ month & $112(39.6 \%)$ & $28(40.6 \%)$ & $0.42(0.09-1.9)$ & $0.23(0.04-1.2)$ \\
\hline \multicolumn{5}{|l|}{ Income } \\
\hline$\leq 30$ USD & $206(72.8 \%)$ & $62(89.8 \%)$ & 1.00 & 1.00 \\
\hline$>30$ USD & $77(27.2 \%)$ & $7(10.2 \%)$ & $3.31(1.45-7.54)$ & $2.11(0.85-5.19)$ \\
\hline \multicolumn{5}{|c|}{ Distance from H.C } \\
\hline$\leq 5 \mathrm{~km}$ & $220(77.7 \%)$ & $44(63.4 \%)$ & 1.00 & 1.00 \\
\hline$>5 \mathrm{~km}$ & $63(22.3 \%)$ & $25(36.6 \%)$ & $0.50(0.28-0.88)$ & $0.59(0.3-1.17)$ \\
\hline \multicolumn{5}{|l|}{ Excreta disposal } \\
\hline Use Open field & $10(3.5 \%)$ & $10(14.5 \%)$ & 1.00 & 1.00 \\
\hline Use latrine & $273(96.5 \%)$ & $59(85.5 \%)$ & $4.62(1.84-11.6)$ & $2.62(0.87-7.82)$ \\
\hline
\end{tabular}

\subsection{Identification of Sources of Infection}

$49.6 \%$ of the mothers identified eating contaminated food as a cause. Alternative types of perceived causes of the infection by the mothers in this study included the evil-eye (15.3\%), teething (12.8\%), children being kept for too long without food (11.1\%) and playing in hot areas (22.8\%).

\section{Discussion}

A major reason for the poor health outcomes of children with diarrhea is the treatment of the child by their mother or care-provider. The primary objective of this study was to identify the treatment, including the type of professional treatment sought outside the home, by the mother or careprovider of children with diarrhea in the Arsi Zone, Central Ethiopia.

Despite medical advice to increase fluid intake in diarrhea $[1,7]$, fluid provision was increased in only $34 \%$ of the Ethiopian children. A total of $24 \%$ of the women in the current study had decreased or stopped fluids, results much more favorable compared to the results reported for a rural community of Kenya, where more than $70 \%$ of mothers decreased or stopped fluid intake during diarrhea episodes[5, 12, 13].

This difference is, however, notable compared to other studies, such as those performed in Afghanistan and India[12,14,15], which reported increased fluids being provided in only of $9 \%$ and $6 \%$ of the children, respectively . Fluid intake was unchanged in $31.8 \%$ of urban and $24.2 \%$ of rural children and, although this is higher than the $19 \%$ reported in the 2005 Demographic and Health Survey (DHS) of Ethiopia, it is lower than a study in India where $40 \%$ of the respondents gave the usual amount of fluid $[5,12]$.

Of interest are the results on the form of rehydration therapy sought by the women in the current study. Only $25 \%$ of children were treated with ORS compared to studies in rural Vietnam and India, where $43 \%$ and $61.1 \%$ of children with diarrhea received ORS, respectively $[14,15]$.

Eighty-six percent of the respondents requested help when their child contracted diarrheal disease. Of these, $60.4 \%$ of mothers went to health institutions that are considered modern health care in the present study. This is consistent with a study in Nepal, where approximately $50 \%$ of the children with diarrhea under the age of five were taken to a health care facility[16]. Notable differences, however, existed according to the site of residence of the women in the Arsi zone. Whereas $70 \%$ of children in urban areas attended a health facility, the figure deceased to $54.4 \%$ in rural areas. Although these figures are much higher than the $14.9 \%$ and $26.4 \%$ reported for rural communities in Kenya[13] and Western Nepal[17], respectively, they remain similar to another Ethiopian study in which $86.4 \%$ of urban children and $45.5 \%$ of rural children with diarrhea were taken to health care provider [6].

Multivariate analysis result showed a significant association between place of residence and the seeking of modern treatment $(\mathrm{p}<0.05)$, with urban mothers being four and half times more likely to have sought modern treatment than rural dwellers [OR $(95 \%$ CIs $)=4.49(2.07,9.7)]$. The association of the distance of modern health care facilities, the educational status of the women, the household income and latrine usage with modern health-seeking behavior of mothers was consistent with a previous study [17].

Most episodes of childhood diarrhea last one to seven days and are characterized by frequent loose or watery stools. Deaths associated with this type of diarrhea result from dehydration and it is important to seek medical advice as soon as possible. Only $54.3 \%$ (67.9\% urban and $45.7 \%$ rural) of the women sought medical assistance within a two-day period. These results indicate that women, especially those in rural areas, do not yet understand the potentially serious consequences of diarrhea until it is too late.

The most common cause of severe diarrhea in children throughout the world is intestinal infection which, with its accompanying loss of fluid and electrolytes, may progress rapidly to cause dehydration[18]. Knowledge of the causes of such infection remains a problem. Only $49.6 \%$ of the mothers identified eating contaminated food as a cause. Although less than half of the mothers identified food as a possible cause, 
this result is an improvement on a previous study where only $3.6 \%$ of the mothers knew that microorganisms [10] were the cause of diarrhea, while in Pakistan only $26 \%$ of mothers said contaminated food is the cause of diarrhea $[10,19]$.

Limitations of the study: The study was employed using interviewer administrated questioner that might result social desirability bias.

\section{Conclusion}

In conclusion, the study points out a number of factors that influence healthcare-seeking behavior of the mother/careproviders. Access to child health services, their site of residence, educational status, and income are among the variables positively associated with modern health careseeking behaviors. Despite the available information, only a third of the women gave their sick child increased fluids and approximately half of the women perceived contaminated food to be a potential source of infection causing diarrhea. These results demonstrate urgency for improved education and economic circumstances for women and improvements in health education and infrastructure. Such in access to modern health care are essential to help overcome childhood diarrhea with its attendant morbidities and mortalities.

\section{Authors' Contributions}

EM, TM and AW were involved in the design, conception, and conduct of the study, the analysis and interpretation of the findings. TM, EM and TD: involved in analysis, interpretation and writes up of the manuscript. All the authors read and approved the final content of the manuscript.

\section{Acknowledgements}

The authors gratefully acknowledge all the participants and data collectors. The authors gratefully acknowledge editorial help as part of the Nextgenediting Global Initiative

\section{Authors' Information}

EM: Lecturer at Department of Public Health, Faculty of Health Sciences, Assosa University.

TM: Lecturer at School of Public Health, College of Health Sciences, Wolaita Soddo University.

AW: Associate Professor, School of Public Health, College of Medical and Health Sciences, Addis Ababa University.

TD: Lecturer at School of public Health, College of Health Sciences, Wolaita Soddo University.

EL: Disease Prevention and Control Officer, Hadiya Zonal Health Department, Hossana, Ethiopia.

\section{References}

[1] Umesh DP, Joseph SB, Roger IG: The global burden of diarrhoeal disease in children. Bulletin of the World Health Organization 2003, 81(4):236.
[2] The United Nations Children's Fund (UNICEF)/World Health Organization (WHO): Diarrhea: Why children are still dying and what can be done. In.: WHO Press; 2009.

[3] Rishi P, Feleke A, Lawrence H, Yifru S, R.Bradley S: Risk Factors and Case Management of Acute Diarrhea. J Health Population Nutr 2010, 28(3):253-263.

[4] Merita B, Sanije H.G, Musli G, Naser. R: Maternal Practice on Management of Acute Diarrhea. TAF Prev Med Bull 2009, 8(5):369-372.

[5] CSA: Ethiopian demographic and health survey2005,Addis Ababa,. In.; 2006.

[6] Assefa T, Belachew T, Tegegn A, Deribew A: Mothers' health care seeking behavior forchildhood illnesses in Derra District, North ShoaZone. Ethiopian Journal of Health Science 2008, 18(3):87-93.

[7] World Gastroenterology Organisation: World Gastroenterology Organisation Global Guidelines: Acute diarrhea in adults and children: a global perspective. 2012.

[8] Semba R, Bloem M: Nutrition and Health in Developing Countries. Totowa, NJ: Humana Press 2000.

[9] Negussie T, Chepngeno G: Determinants of health care seeking for childhood illnesses in Nairobi slums. Tropical Medicine and International Health 2005, 10(3):240-245.

[10] Sodamann M, Jakobsen MS, Molbak K, Martins C: Aaby P.managment of childhood diarrhea and use of oral rehydration salts. Am J Trop Med Hyg 1999, 60(1):167171.168.

[11] Federal Democratic Republic of Ethiopia Population Census Commission: Summary and Statically Report of the 2007 Population and Housing Census. In. Edited by CSA. Addis Ababa; 2008.

[12] Kaur A, Chowdhury S, Kumar R: Mothers' Beliefs and Practices Regarding Prevention and Management of Diarrheal Diseases. Indian Pediatrics January 1994, 31.

[13] Doreen M, Othero A S, Orago S, Groenewegen T, Kaseje O, A OP: Home Management of Diarrhea among Under fives in a Rural Community in Kenya: Household Perceptions and Practices. East African Journal of Public Heath 2008, 5(3):142-146

[14] Tang Kim H, Michael JD, Tran T: Factors affecting utilization of health care services by mothers of children ill with diarrhea in rural Vietnam. South East Asian j trop med public health 2003, 34(1).

[15] Deshmu k, Dongre AR, Sinha N, Garg B: Acute childhood morbidities in rural Wardha. 2009, 63(8):345-354.

[16] 2006 NDaHS: Ministry of Health and Population. New ERA, and Macro International Inc Kathmandu, Nepal 2007.

[17] Ansari M, Palaian S, M II: The role of mothers in the management of child hood diarrhea in Nepal. Australia medical journal 2009, 1(14):235-238.

[18] WHO: The World Health report, shaping the future. In. Geneva; 2003.

[19] Nielsen M, Hoogvorst A, Konradsen F, Mudasser1 M, Hoek3 Wvd: cause of childhood diarrhea as perceived by mother. South East Asian J Trop Med Public Health June 2003, 34(2). 